\title{
Polymer Matrix Composite in High Voltage Applications: A Review
}

\author{
Satish Bhalerao $^{1}$ (D), Nitin Ambhore 2,* (D), Munjadas Kadam 1 (D) \\ 1 Department of Mechanical Engineering, Jawaharlal Nehru Engineering College, Aurangabad, MS India; \\ satishbhalerao@gmail.com (S.B.); munjadaskadam@jnec.ac.in (M.K.); \\ 2 Department of Mechanical Engineering, Vishwakarma Institute of Information Technology, Pune, MS India; \\ nitin.ambhore@viit.ac.in (N.A.); \\ * Correspondence: nitin.ambhore@gmail.com;
}

Scopus Author ID 56986482000

Received: 22.10.2021; Revised: 20.11.2021; Accepted: 22.11.2021; Published: 10.12.2021

\begin{abstract}
In recent years, natural fibers have become more widely used as reinforcement in polymer composites to generate low-cost products. Fibrous reinforcements in polymer matrices lead to good mechanical and electrical properties for composite materials. Depending on the grade and orientation, composites can be one-fifth the weight of steel while offering similar or better stiffness and strength. In addition, unlike steel or aluminum, composites do not rust or corrode. Composite materials reinforcing phase gives durability, strength, and stiffness. Composite materials have traditionally been employed as structural materials. Composite materials are increasingly being used in electrical applications such as bushings, circuit breakers, coupling capacitors, and so on, thanks to the growing growth of the electrical sector. The design parameters for structural and electrical composites differ dramatically due to the enormous differences in property requirements. Depending on the application, structural composites. Structural composites prioritize sufficient strength and modulus, while electrical composites prioritize superior dielectric constant, thermal conductivity and low thermal expansion, and shielding effectiveness. In the electrical industry, low density is desired because it allows for weight reduction. It is also desirable to have a high strength-weight ratio and dielectric properties. This paper provides a brief review of the properties of polymer composite materials and their application in the high voltage industry.
\end{abstract}

Keywords: composite materials; polymer matrix; mechanical properties; dielectric properties.

(C) 2021 by the authors. This article is an open-access article distributed under the terms and conditions of the Creative Commons Attribution (CC BY) license (https://creativecommons.org/licenses/by/4.0/).

\section{Introduction}

In today's era of industrial applications, composite materials have become a requirement rather than a compulsion. This situation has prompted the industry to seek out superior alternative materials available at reasonable prices to preserve the required price margin, although traditional materials are depleting natural resources. Composite materials are being extensively used in aerospace, automobiles, military, and medical sciences. The uniqueness of these materials is that they offer a highly appealing combination of toughness, stiffness, lightweight, and corrosion-resistant characteristics[1,2]. Composite materials, particularly polymer-based composites, have attracted special attention in the high voltage industry due to their outstanding mechanical properties and excellent thermal and great dielectric strength. There are several types of equipment such as a transformer, circuit breaker, disconnector, and current transformer, wherein various parts are made of composite materials. 
These parts mainly include an insulator, switching rod, gears, arching contact, etc. All this equipment is required to work consistently and reliable manner so that there should not be any power failure. With this background, the need arises to have low weight and high strength material, which should satisfy the mechanical and electrical requirements. Many traditional metals/materials have been replaced by polymers composite in diverse applications over the last few decades. The properties of polymers are modified by using to suit the high strength/high modulus requirements. In the electrical industry, reinforced polymers are widely used because of their high strength and low weight. It is also used to satisfy electrical properties like dielectric strength and in high-temperature applications such as circuit breakers and isolators[3,4]. This paper provides a brief overview of the application of composite materials and their properties in the high voltage sector.

\section{Composite Materials}

The matrix and reinforcing phases are two common classifications for composite materials.

\subsection{Matrix phase.}

\subsubsection{Metal Matrix Composites(MMC).}

These are prepared from the metal matrix, mostly aluminum, cobalt, magnesium, iron, copper, titanium, and a reinforcing phase of dispersed ceramic or phase [3,5]. The selection of matrix materials is based on the application's desired properties and service conditions. The amount of reinforcement used might be up to $50 \%$ of the overall volume of the composite. The reinforcement such as $\mathrm{SiC}$ particles, boron and $\mathrm{Al}_{2} \mathrm{O}_{3}$, and Borsic and $\mathrm{TiB}_{2}$ coated carbon can be combined quickly and effectively. Aluminum and titanium are the two most often utilized metal matrices in the automotive and aerospace field due to remarkable strength at high temperatures and strong resistance to corrosion [6-8].

\subsubsection{Ceramic Matrix Composites(CMC).}

These are comprised of a ceramic matrix reinforced with a ceramic matrix such as aluminum oxide, carbon, silicon nitride. Ceramics have very attractive properties for many applications; high toughness and stability at high temperatures and wear resistance are widely utilized for aerospace applications. A particular property can be obtained based on short and long fiber. The toughness of the short-Ceramic Matrix Composite improves its resistance to crack propagation and, on the other hand, has a catastrophic failure mode. The dispersed phase in continuous monofilaments provides the best strengthening effect[9-11].

\subsection{Reinforcement phase.}

Reinforcement such as carbon, glass, metal, kevlar is embedded in the matrix. These are typically hard and give excellent strength, stiffness, and temperature, and wear resistance. Reinforcements can be utilized in the form of particles, sheets, and whiskers and are mainly to carry the applied load to the composite. Nowadays, glass is extensively used for manufacturing car parts, boat hulls, sports utensils, decorative panels for buildings. Recent research has revealed that the reinforcement material silicon carbide particles, boron nitride, aluminum 
oxides, and zinc oxide are best for polymers matrix to achieve specific mechanical and electrical properties [1-2,12].

\section{Composite Materials In High Voltage Applications}

The voltage in the range $33 \mathrm{kV}-220 \mathrm{kV}$ is referred to as high voltage. The development of composites has gained a lot of interest in high-voltage applications, mainly including bushings, insulators, circuit breakers, coupling capacitors. Composite material has attracted special attention in the high-voltage industries due to its outstanding mechanical and dielectric strength. The desired properties are obtained by combining two distinct materials [13]. There are three major types of composites depending on the matrix material: ceramic matrix composites, metal matrix composites, and polymer matrix composites[14]. Among these, polymer-based composites are found mostly in electrical and mechanical applications because of their excellent specific properties. They offer a low-cost and easy fabrication method. Figure 1 presents the application of polymer composites in high voltage components.

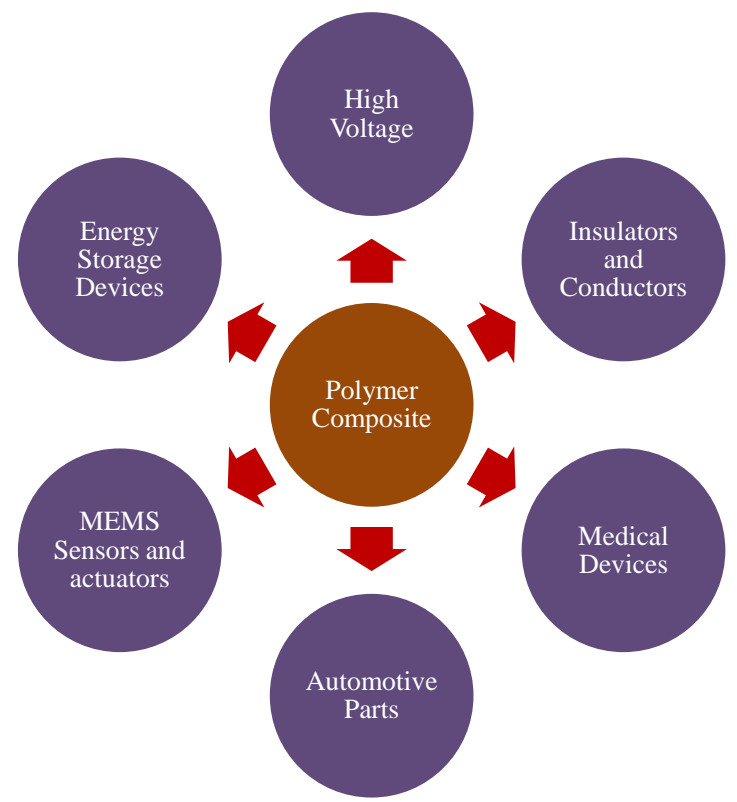

Figure 1. Application of polymer composites.

Various reinforcement materials such as glass, carbon are employed for polymer matrix composites(PMC). Glass has been widely used as reinforcement in the design of transmission lines and insulators, transmission towers[15,16]. This polymer can work temperature up to $200^{\circ} \mathrm{C}$, and at a higher temperature, the glass-based polymers begin to flow. Other most commonly used polymers for high voltage are carbon-based and Kevlar-based polymers. These are used in energy storage devices, fuel cells, capacitors, transmission cables. They can retain their strength at elevated temperatures. Polymers, in general, are categorized into two groups: thermoplastics and thermosets. Thermoplastics have the ability to mold in any shape when heated and harden when cooled.

On the other hand, the curing process forms a rigid three-dimensional structure in thermoset polymer. The thermoset polymer cannot melt due to cross-links when subjected to higher temperatures, providing good electrical and thermal insulation properties. Epoxy, polyester, vinyl ester, and phenolic resins are the most regularly used thermoset resins. Thermoset resins can be designed to provide a wide range of qualities depending on the 
application. Thermosets polymer is more stable than thermoplastics involved in the structure[17-21]. Figure 2 shows the structure of a thermoplastic and thermosetting polymer.

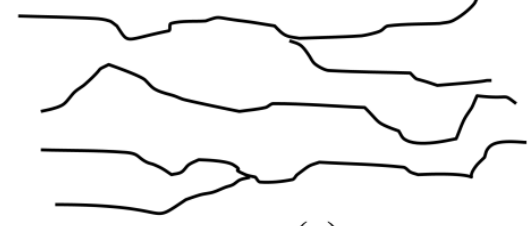

(a)

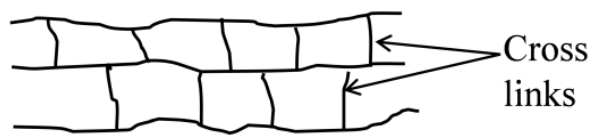

(b)

Figure 2. The structure of (a) thermoplastic polymer and (b) thermosetting polymer.

\section{Mechanical and Dielectric Properties of Polymer Matrix Composites}

Polymer composite employed in high-voltage applications must withstand mechanical and thermal loads. There is a substantial quantity of literature on the mechanical properties of composite materials. Several researchers have reported the experiential procedure to obtain mechanical properties. For high voltage applications, the composites must possess good dielectric strength. This section presents a brief overview of polymer composite materials' mechanical and dielectric properties used in high voltage applications.

\subsection{Mechanical properties.}

Mechanical properties of composites depend upon several factors such as matrix, reinforcement, volume fraction, type and orientation, working temperature, and manufacturing process [21-23]. The properties of composites material cannot be represented by any of its constitutes. Mechanical properties such as tensile and bending strength, elastic modulus, and thermal properties have been studied by various researchers [24-26]. Polymer matrix composites have found enhanced specific tensile strength compared to traditional composites. Material with higher strength is desirable for various electrical equipment. Table 1 shows the mechanical properties of various polymer matrix composites.

Table 1. Properties of various PMC composites [27].

\begin{tabular}{|c|c|c|c|c|c|}
\hline Materials & $\begin{array}{l}\text { Tensile } \\
\text { Strength } \\
\text { (GPa) }\end{array}$ & $\begin{array}{l}\text { Density } \\
\left(\mathrm{g} / \mathrm{cm}^{3}\right)\end{array}$ & $\begin{array}{l}\text { Elastic } \\
\text { modulus }\left(10^{2}\right. \\
\text { GPa })\end{array}$ & $\begin{array}{l}\text { Specific } \\
\text { strength } \\
\left(10^{6} \mathrm{~cm}\right)\end{array}$ & $\begin{array}{l}\text { Specific } \\
\text { modulus } \\
\left(10^{8} \mathrm{~cm}\right)\end{array}$ \\
\hline Steel & 1.03 & 7.80 & 2.10 & 1.30 & 2.70 \\
\hline Aluminum alloy & 0.47 & 2.80 & 0.75 & 1.70 & 2.60 \\
\hline Titanium alloy & 0.96 & 4.50 & 1.14 & 2.10 & 2.50 \\
\hline Glass composite materials & 1.06 & 2.00 & 0.40 & 5.30 & 2.00 \\
\hline Carbon II/epoxy composite materials & 1.50 & 1.45 & 1.40 & 10.30 & 9.70 \\
\hline Carbon I/epoxy composite materials & 1.07 & 1.60 & 2.40 & 6.70 & 15.00 \\
\hline Organic /epoxy composites & 1.40 & 1.40 & 0.80 & 1.00 & 5.70 \\
\hline Boron /epoxy composites & 1.38 & 2.10 & 2.10 & 6.60 & 10.00 \\
\hline Boron /aluminum matrix composites & 1.00 & 2.65 & 2.0 & 3.80 & 7.50 \\
\hline
\end{tabular}

Huang et al. [21] reported a review on the properties of polymer-based composites. The authors' focus was mostly on the interface and interfacial properties of polymer-based composites. Some interfacial mechanisms, as well as methods for measuring interfacial characteristics, have been presented. Another review paper by Mahesh et al. [23] reported an extensive review on an acceptable combination of fiber and matrix for impact loading applications. They developed an approach based on density, tensile strength and modulus, and cost characteristics. Their focus, however, was on choosing the right fiber and matrix for energy 
absorption and preventing failure when subjected to impact loads. In contrast, the mechanical and dielectric properties of polymer composites focus on our research.

Numerous properties of polymer composites with attributes such as matrix, reinforcement, volume fraction, type and orientation, working temperature, and manufacturing process have been examined by several researchers, and it is reported in a subsequent section. Jiang et al. [24] experimentally investigated the effect of moisture absorption on the flexural characteristics of Glass fiber reinforced polymer (GFRP) laminates for wet and hot conditions. The experimental finding reveals that their stiffness and flexural strength decrease when combined moisture and temperature influences.

Al-Mosawi et al. [28] evaluated the mechanical properties of Araldite matrix composites reinforced with hybrid palms-Kevlar. The reinforcement percentage have been varied as $20 \%, 40 \%$, and $60 \%$, and their effect on mechanical properties such as impact, tensile, flexural strength, and hardness was studied. It is concluded that the improvement in mechanical properties increases with an increasing percentage of reinforcement. Vasudevan et al. [29] evaluated of tensile properties of the GFRP. The flexural and tensile properties of the composite were compared with finite element analysis(FEA) results. It is revealed that the composite had good characteristics that matched the FEA results.

Agunsoye et al. [30] looked into the tensile and strain properties of new polymeric composites based on Delonix regia. According to the findings, the presence of vacancy within the composite harmed the tensile strength and strain of the composite at $10 \%$ Delonix regia seed particle addition. At $4 \mathrm{wt} \%$, maximum increases in tensile strength and strain of about 300 percent and $41 \%$ were observed. However, the flexural characteristics of the PMC were improved when the volume of continuous carbon increased from 50 to $70 \%$ in an epoxy-based polymer matrix, according to $\mathrm{He}$ and Gao [31].

Mohanty and Srivastava[32] investigated the effect of alumna on the short glass/carbon reinforced epoxy-based composites. According to the findings, alumina particles of $2 \mathrm{wt} \%$ improve mechanical properties like flexural strength and modulus and impact strength. In another study, Song et al. [33] investigated the mechanical properties of an acrylonitrilestyrene-acrylate polymer with the help of carbons. The findings revealed that the mechanical properties had been enhanced largely by the carbons. The tensile strength is increased by $148 \%$ when carbon fiber is changed to $30 \%$. Enhancement in flexural strength and the flexural modulus is observed as $122 \%$ and $464 \%$, respectively.

Li et al. [34] investigated the shear strength of carbon /epoxy composites using the electrochemically oxidizing method. They observed an improvement in shear strength by 24.7\%. Ibitoye et al.[35] studied the mechanical properties of SiC-treated recycled high-density polyethylene (RHPE). The addition of SiC to RHPE was found to improve tensile and impact strength, elastic modulus, and stiffness. In contrast, the ductility of composite materials appears to be decreasing.

Haneefa et al. [36] obtained the tensile and flexural properties of banana and glassreinforced Polystyrene composites. It has been found that increasing the volume component of the glass fiber increases the composite's stiffness and modulus. Experiments have shown that chemically modified composites have $30 \%$ better mechanical characteristics than unmodified composites.Ozawa et al. [37] performed bending and tension tests on solid and hollow composite material at $298 \mathrm{~K}$ and relative humidity of $50 \%$. The density for the solid bar was doubled that of a hollow bar. The results showed that the load-displacement response of solid 
and hollow bar in tension tests is linear. However, the bending test results exhibit non-linear behavior.

As may be observed from the preceding discussion, various mechanical properties such as tensile and bending strength, flexural strength, elastic modulus, and thermal properties have been studied and can be improved by varying reinforcement percentages.

\subsection{Dielectric properties.}

Composite materials are very useful for dielectric applications. Modern electrical devices demand materials with high dielectric constant, low dielectric loss, and increased dielectric strength. The dielectric property is very important in designing an insulating system of an electric system. Nanodielectrics with polymer matrix, particularly epoxy resin, attracted various research in insulating systems due to their appealing properties. Furthermore, the dielectric property of polymer composites, the interface between fillers and the polymers, have shown improved dielectrics properties, which have used numerous high-voltage applications, such as motors, generators, wire and cables, and energy storage devices[15,16]. To achieve a superior dielectric constant, polymer-based composite with other dielectric materials such as ceramic are combined. Some glass-based resins are preferred to increase dielectric properties. Table 2 represents the dielectric property for various glass resins.

Table 2. High-frequency dielectric properties of glass [27].

\begin{tabular}{l|l|l|l|l}
\multirow{2}{*}{ Types of or resin } & \multicolumn{2}{l|}{ Dielectric constant } & Dissipation factor \\
\cline { 2 - 5 } & $\mathbf{1 ~ M H z}$ & $\mathbf{9 . 3 7 5} \mathbf{~ G H z}$ & $\mathbf{1 ~ M H z}$ & $\mathbf{9 . 3 7 5} \mathbf{~ G H z}$ \\
\hline E-glass & 5.8 & 6.13 & 0.001 & 0.0039 \\
\hline S-glass & 4.35 & 5.21 & 0.002 & 0.0068 \\
\hline D-glass & 3.56 & 4 & 0.0005 & 0.0026 \\
\hline High silica & - & 3.78 & - & 0.002 \\
\hline Polyster 301 & $3.4-3.6$ & - & $0.015-0.016$ & -
\end{tabular}

Yang et al. [14] investigated the influence of particle size on the dielectric characteristics of CCTO/PVDF material. The findings of this study suggest that a composite incorporating microsized CCTO is appropriate for embedded device applications.

Li et al. [38] investigated dielectric, thermal, and mechanical properties of PI/PSF-X compounds through an experimental test. Experimental results indicated that composite films have strong thermal, dielectric, and mechanical properties, making them suitable for use in electronic devices under severe conditions, especially high-temperature situations.

Zhang et al. [39] investigated a nanoscale polymer matrix made of $\mathrm{CaCu}_{3} \mathrm{Ti}_{4} \mathrm{O}_{12}(\mathrm{CCTO})$ particles as filler and copolymer $\mathrm{P}(\mathrm{VDF}-\mathrm{TrFE})$. The amount of CCTO in the composites varies between 0 and $50 \%$ of the overall volume. The dielectric characteristics ranged from $0.1 \mathrm{kHz}$ to $100 \mathrm{kHz}$, and temperature ranged from $200 \mathrm{~K}$ to $370 \mathrm{~K}$. The results show that increasing the CCTO component decreases the dielectric constant with increasing frequency. However, the constant dielectric increases with increasing temperature.

Thomas et al. [40] reported dielectric loss exhibited no fluctuation up to 40 percent CCTO loading but showed an increasing trend after that. The results found a dielectric constant of 95 at room temperature at $100 \mathrm{~Hz}$ for 55 volume percent of CCTO in PVDF. Singha et al. [41] investigated the dielectric behavior of epoxy nanocomposites with individual nanofillers made of $\mathrm{Al}_{2} \mathrm{O}_{3}$ and $\mathrm{TiO}_{2}$ at low filler concentrations in a frequency range from $1000 \mathrm{kHz}$ to $10^{5} \mathrm{kHz}$. The experimental results showed dielectric properties different from those of the microcomposites. It can also be seen that for the frequencies considered. There is a strong 
dependence of the permittivity and concentration of the filler on the equivalent permittivity of the nanocomposite material.

Kochetov et al. [42] investigated dielectric spectroscopy of epoxy-based nanocomposites containing several types of particles, including $\mathrm{SiO}_{2}, \mathrm{Al}_{2} \mathrm{O}_{3}, \mathrm{AlN}$, and $\mathrm{BN}$. The research focuses on an analysis of the complex permittivity. It is reported that the below 5 weight $\%$ of filler results in a decrease in the polymer.

Arbatti et al. [43] examined the dielectric constant of ceramic-polymer. The authors conclude that, at $100 \mathrm{~Hz}$, the dielectric constant of the composites exceeds 600 at ambient temperature and 1200 at $70^{\circ} \mathrm{C}$. The high dielectric constant is partly due to the contribution of heterogeneous relaxation. Triki et al. [44] investigated the dielectric properties of unsaturated polyester reinforced with natural fibers for a frequency range of $101 \mathrm{~Hz}$ to $106 \mathrm{~Hz}$ and a temperature range of $400^{\circ} \mathrm{C}$ to $150^{\circ} \mathrm{C}$. At low frequencies, the permittivity reaches high values with increasing temperatures. It is worth noting that the dielectric constant at low temperatures is constant and approximately equal to that of polyester resin, indicating the absence of polarization of the water dipole. Yakovenko et al. [45] investigated Larit285 low-viscosity epoxy polymer matrix with the H285 curing agent and the filler MWCNTs. The MWCNTs content was varied from 0.05 to $1 \mathrm{wt} \%$. It is revealed that dielectric permittivity increases as the MWCNT \% increases.

Shen et al. [46] studied the interfacial effect on dielectric properties of Core/ShellStructured Particles polymer composites. The electrical characteristics of the interlayers are said to have a significant impact in shaping the dielectric behavior of nanocomposites. The thickness of the interlayers may be adjusted to modify the nanocomposite's stable dielectric constants. Compared to conventional composite, The similar dielectric behavior of composite can be obtained by increasing the conductivity of the interlayer. Tunable dielectric constants have been produced in the Shell 8 and Shell 13 nanocomposites by altering the thickness of the organic insulating shells, and their dielectric constants are virtually frequency-independent throughout a wide frequency range.

\section{Conclusions}

In this paper, various mechanical and dielectric properties of polymer matrix composite have been presented. Mechanical properties like tensile strength, flexural strength, modulus, impact strength are improved by varying reinforcement percentages. Some of the findings reveal that moisture and temperature influence mechanical strength and the properties such as stiffness and flexural strength decrease with an increase in temperature. Electrical devices require better mechanical and dielectric properties, materials with high dielectric constant, low dielectric loss, and increased dielectric strength. The dielectric property is very important in designing an insulating system of an electric system. The required dielectric properties of the composite can be obtained with proper combinations of matrix and reinforcement phases. Polymer matrix made of $\mathrm{CaCu}_{3} \mathrm{Ti}_{4} \mathrm{O}_{12}$ (CCTO) particles improves dielectric strength. The polymer composites are preferred due to their high strength-to-weight ratio and high dielectric properties. It is found that polymer composite shows excellent mechanical and dielectric and are best suited for high voltage applications.

\section{Funding}

This research received no external funding. 


\section{Acknowledgments}

The authors declare no acknowledgments.

\section{Conflicts of Interest}

The authors declare no conflict of interest.

\section{References}

1. Javidan, M.M.; Kim, J. Experimental and Numerical Sensitivity Assessment of Viscoelasticity for Polymer Composite Materials. Sci Rep 2020, 10, 675,https://doi.org/10.1038/s41598-020-57552-3.

2. Rajak, D.K.; Pagar, D.D.; Kumar, R.; Pruncu, C.I. Recent progress of reinforcement materials:a comprehensive overview of composite materials.J.Mater.Res.Technol. 2019, 8,6354-6374, https://doi.org/10.1016/j.jmrt.2019.09.068.

3. Hadi, J.M.; Aziz, S.B.; Mustafa, M.S.; Hamsan, M.H.; Abdulwahid, R.T.; Kadir, M.F.Z.; Ghareeb H.O. Role of nano-capacitor on dielectric constant enhancement in PEO: $\mathrm{NH}_{4} \mathrm{SCN}: \mathrm{XCeO}_{2}$ polymer nanocomposites: Electrical and electrochemical properties. J. Mater. Res. Technol. 2020, 9, 92839294,https://doi.org/10.1016/j.jmrt.2020.06.022.

4. Jayamani, E.; Nair, G.A.; Soon, K. Investigation of the dielectric properties of natural fibre and conductive filler reinforced polymer composites.Materials Today: Proceedings 2020, 22,162-171, https://doi.org/10.1016/j.matpr.2019.08.032.

5. Zhao, Z.; Bai, P.; Du, W.; Liu, B.; Pan, D.; Das, R.; Liu, C.; Guo, Z. An overview of graphene and its derivatives reinforced metal matrix composites: Preparation, properties and applications. Carbon 2020, 170, 302-326, https://doi.org/10.1016/j.carbon.2020.08.040.

6. Zhang, X.; Hu, T.; Rufner, J.F.; LaGrange, T.B.; Campbell, G.H.; Lavernia, E.J.; Schoenung, J.M.; Benthem, $\mathrm{K}$. Metal/ceramic interface structures and segregation behavior in aluminum-based composites. Acta Materialia 2015, 95, 254-263, http://dx.doi.org/10.1016/j.actamat.2015.05.021.

7. Mallick, P.K. 2 - Advanced materials for automotive applications: an overview. In: Advanced Materials in Automotive Engineering 2012, 5-27, Woodhead Publishing, https://doi.org/10.1533/9780857095466.5.

8. Adebisi, A.A.; Maleque, M.A.; Rahman, M.M. Metal matrix composite brake rotor: Historical development and product life cycle analysis. International Journal of Automotive and Mechanical Engineering 2011, 4, 471-480, http://dx.doi.org/10.15282/ijame.4.2011.8.0038.

9. Boccaccini, D.;Cannio, D.;Bernardo, E.;Boccaccini, A.R. Glass and Glass-Ceramic Matrix Composites for Advanced Applications: Part I: Properties and Manufacturing Technologies. In: Encyclopedia of Materials: Technical Ceramics and Glasses 2021, 2, 277-287, Elsevier, https://doi.org/10.1016/B978-0-12-8185421.00079-5.

10. Krenkel, W.; Flauder, S.; Puchas, G. Short Ceramic Matrix Composites (SF-CMCs), Encyclopedia of Materials: Technical Ceramics and Glasses 2021, 2, 260-276, https://doi.org/10.1016/B978-0-12-8185421.00071-0.

11. Zachariah, S.A.; Shenoy, S.; Pai, D. Experimental analysis of the effect of the woven aramid fabric on the strain to failure behavior of plain weaved carbon/aramid hybrid laminates. Facta UniversitatisSeries: Mechanical Engineering 2021, 1-13, https://doi.org/10.22190/FUME200819022Z.

12. El-Abbassi, F.E.; Assarar, M.; Ayad, R.; Bourmaud, A.; Baley, C. A review on alfa fibre (Stipa tenacissimaL.): From the plant architecture to the reinforcement of polymer composites.Composites Part A: Applied Science and Manufacturing2020, 128, 105677,https://doi.org/10.1016/j.compositesa.2019.105677.

13. Wang, J.W.; Wang, Y.; Wang, F.; Li, S.Q.; Xiao, J.; Shen, Q.D. A large enhancement in dielectric properties of poly(vinylidene fluoride) based all-organic nanocomposites.Polymer 2009, 50, 679-684, https://doi.org/10.1016/J.POLYMER.2008.11.040.

14. Yang, W.; et al. A novel all-organic DIPAB/PVDF composite film with high dielectric permittivity.Journal of Materials Science: Materials in Electronics 2009, 28, 9658-9666, https://doi.org/10.1007/s10854-0176716-x.

15. Ali, H.T.; Akrami, R.; Fotouhi, S.; Pashmforoush, F.; Fragassa, C.; Fotouhi, M. Effect of the stacking sequence on the impact response of carbon-glass/epoxy hybrid composites. Facta Universitatis Series: Mechanical Engineering 2020, 18, 69-77, https://doi.org/10.22190/FUME191119010A. 
16. Pleşa, I.; Noţingher, P.V.; Schlögl, S.; Sumereder, C.; Muhr, M. Properties of Polymer Composites Used in High-Voltage Applications.Polymers 2016, 8,173, https://doi.org/10.3390/polym8050173.

17. Zhang, D.; He, M.; Qin, S.; Yu, J. Effect of length and dispersion on properties of long glass reinforced thermoplastic composites based on poly(butylene terephthalate). RSC Advances. 2017, 7,15439-15454, https://doi.org/10.1039/C7RA00686A.

18. Babu, U.H.; Sai, N.V.; Sahu, R.K. Artificial intelligence system approach for optimization of drilling parameters of glasscarbon/polymer composites. Silicon 2021, 13, 2943-2957, https://doi.org/10.1007/s12633020-00637-5.

19. Dharmavarapu, P.; Reddy, M. Mechanical, low velocity impact, fatigue and tribology behaviour of silane grafted aramid fibre and nano-silica toughened epoxy composite. Silicon 2021,13, 1741-1750, https://doi.org/10.1007/s12633-020-00878-4.

20. Khan, Z.I.; Arsad, A.; Mohamad, Z.; Habib, U.; Zaini, M.A.A. Comparative study on the enhancement of thermo-mechanical properties of carbon and glass reinforced epoxy composites. Materials Today: Proceedings 2021, 39, 956-958, https://doi.org/10.1016/j.matpr.2020.04.223

21. Huang, S.; Fu, Q.; Yan, L.; Kasal, B. Characterization of interfacial properties between fibre and polymer matrix in composite materials -A critical review. J. Mater. Res. Technol. 2021, 13,1441-1484, https://doi.org/10.1016/j.jmrt.2021.05.076.

22. Irwin, P.; Zhang, W.; Cao, Y.; Fang, X.; Tan, D.Q. Mechanical and thermal properties.In: Dielectric Polymer Nanocomposites 2010,163-169, Nelson J.K. (Ed), Springer New York, NY, USA, https://doi.org/10.1007/978-1-4419-1591-7.

23. Mahesh, V.; Joladarashi, S.; Kulkarni, S.M. A comprehensive review on material selection for polymer matrix composites subjected to impact load. Defence Technology 2021, 17, 257-277, https://doi.org/10.1016/j.dt.2020.04.002.

24. Jiang, X.; Song, J.; Qiang, X.; Kolstein, H.; Bijlaard, F. Moisture Absorption/Desorption Effects on Flexural Property of Glass-Fiber-Reinforced Polyester Laminates: Three-Point Bending Test and Coupled HygroMechanical Finite Element Analysis. Polymers 2016, 8, 290, https://doi.org/10.3390/polym8080290.

25. Gudipudi, G.; Nagamuthu, S.; Subbian, S.K.; Rao, S.P. Chilakalapalli. Enhanced mechanical properties of AA6061-B ${ }_{4}$ C composites developed by a novel ultra-sonic assisted stir casting. Engineering Science and Technology, an International Journal 2020, 23, 1233-1243, https://doi.org/10.1016/j.jestch.2020.01.010.

26. Aklilu, G.; Adali. S.; Bright, G. Tensile behaviour of hybrid and non-hybrid polymer composite specimens at elevated temperatures, Engineering Science and Technology, an International Journal 2019, 23, 732-743, https://doi.org/10.1016/j.jestch.2019.10.003.

27. Wang, R.M.; Zheng, S.R.; Zheng, Y.P. Polymer Matrix Composites and Technology, $1^{\text {st }}$ ed. 2011, 1-56, Woodhead Publishing.

28. Al-Mosawi, A.I.; Al-Maamori, M.H.; Wetwet, Z.A. Mechanical properties of composite material. Reinforcing by natural-synthetics. Academic Research International 2012, 3, 108-112.

29. Vasudevan, A.; Kuman, B.N.; Depoures, V.; Maridurai, M.T.; Mohanavel, V. Tensile and flexural behaviour of glass fibre reinforced plastic - Aluminium hybrid laminate manufactured by vacuum resin transfer moulding technique(VARTM). Materials Today: Proceedings $\quad 2021, \quad 37, \quad 2132-2140$, https://doi.org/10.1016/j.matpr.2020.07.573.

30. Agunsoye, J.O.; Bello, S.A.; Adetola, L.O. Experimental investigation and theoretical prediction of tensile properties of Delonix regia seed particle reinforced polymeric composites. Journal of King Saud University - Engineering Sciences 2017, 31, 70-77, http://dx.doi.org/10.1016/j.jksues.2017.01.005.

31. He, H.W; Gao, F. Effect of volume fraction on the flexural properties of unidirectional carbon/epoxy composites. International Journal of Polymer Analysis and Characterization 2015, 20, 180-189, https://doi.org/10.1080/1023666X.2015.989076.

32. Mohanty, A.; Srivastava, V.K. Effect of alumina nanoparticles on the enhancement of impact and flexural properties of the short glass/carbon reinforced epoxy based composites. Fibers Polym 2015, 16, 188-195, https://dx.doi.org/10.1007/s12221-015-0188-5.

33. Song, J.B.; Liu, X.S.; Zhang, Y.H.; Huang, B.; Yang, W.B. Carbon-reinforced acrylonitrile-styrene-acrylate composites: Mechanical and rheological properties and electrical resistivity. Journal of Applied Polymer Science 2016, 133, 43252, https://doi.org/10.1002/app.43252.

34. Li, Z.; Wu, S.; Zhao, Z.; Xu, L. Influence of surface properties on the interfacial adhesion in carbon/epoxy composites. Surface and Interface Analysis 2014, 46, 16-23, https://doi.org/10.1002/sia.5340. 
35. Ibitoye, S.A.; Adeleke, A.A.; Aramide, F.O; Olawale, J.O.; Tiamiyu, A.O.; Oluwasegun, K.M.; AbdulKareem, T.O., Shittu, M.D. Some Mechanical Properties of SiC-Treated Recycled HDPE. International Journal of Materials and Chemistry 2013, 3, 45-50, http://dx.doi.org/10.5923/j.ijmc.20130303.01.

36. Haneefa, A.; Bindu, P.; Aravind, I.; Thomas, S. Studies on tensile and flexural properties of short banana/glass hybrid reinforced polystyrene composites. Journal of Composite Materials 2008, 42,1471-1489, https://doi.org/10.1177\%2F0021998308092194.

37. Ozawa, Y.; Watanabe, M.; Kikuchi, T.; Ishiwatari, H. Mechanical and thermal properties of composite material system reinforced with micro glass balloons. IOP Conference Series: Materials Science and Engineering 2010, 10, 012094, http://dx.doi.org/10.1088/1757-899X/10/1/012094.

38. Li, P.; Yu, J.; Jiang, S.; Fang, H.; Liu, K.; Hou, H. Dielectric, mechanical and thermal properties of all-organic PI/PSF composite films by in situ polymerization. e-Polymers 2020, 20, 226-232, https://doi.org/10.1515/epoly-2020-0020.

39. Zhang, L.; Shan, X.; Wu, P.; Cheng, Z.Y.Dielectric characteristics of $\mathrm{CaCu}_{3} \mathrm{Ti}_{4} \mathrm{O}_{12} / \mathrm{P}(\mathrm{VDF}-\mathrm{TrFE})$ nanocomposites. Applied Physics A: Materials Science and Processing 2012, 107, 597-602, https://doi.org/10.1007/s00339-012-6836-3.

40. Thomas, P.; Varughese, K.T.; Dwarakanath, K.; Varma, K.B.R. Dielectric properties of Poly(vinylidene fluoride) $/ \mathrm{CaCu}_{3} \mathrm{Ti}_{4} \mathrm{O}_{12}$ composites. Composites Science and Technology 2010, 70, 539-545, https://doi.org/10.1016/j.compscitech.2009.12.014.

41. Singha, S.; Thomas, M.J.Permittivity and tan delta characteristics of epoxy nanocomposites in the frequency range of 1 MHz-1 GHz. IEEE Transactions on Dielectrics and Electrical Insulation 2008, 15, 2-11, https://doi.org/10.1109/T-DEI.2008.4446731.

42. Kochetov, R.; Andritsch, T.; Morshuis, P.H.F.; Smit, J.J. Anomalous behaviour of the dielectric spectroscopy response of nanocomposites. IEEE Transactions on Dielectrics and Electrical Insulation 2012, 19,107-117, https://doi.org/10.1109/TDEI.2012.6148508.

43. Arbatti, M.; Shan, X.; Cheng, Z.Y. Ceramic-Polymer Composites with High Dielectric Constant.Advanced Materials 2007,19, 1369-1372, https://doi.org/10.1002/adma.200601996.

44. Triki, A.; Omri, M.A.; Guicha, M.;Ben Hassen,M.; Arous, M.; Fakhfakh, Z. Studies of dielectric relaxation in natural fibres reinforced unsaturated polyester. Journal of Material Science 2011, 46, 3698-3707, http://dx.doi.org/10.1007/s10853-010-5136-6.

45. Yakovenko, O.S.; Matzui, L.Y.; Vovchenko, L.L.; Oliynyk, V.V.; Launetz. V.L.; Trukhanov, A.V.Dielectric properties of composite materials containing aligned carbon nanotubes. Inorganic Materials 2016, 52, 11981203, https://doi.org/10.1134/S0020168516110182.

46. Shen, Y.; Lin, Y.H.; Nan, C.W. Interfacial Effect on Dielectric Properties of Polymer Nanocomposites Filled with Core/Shell-Structured Particles.Advanced Functional Materials 2007, 17, 2405-2410, https://doi.org/10.1002/adfm.200700200. 